\title{
Effects of icotinib, a novel epidermal growth factor receptor tyrosine kinase inhibitor, in EGFR-mutated non-small cell lung cancer
}

\author{
GUANGDIE YANG* , YINAN YAO, JIANYA ZHOU and QIONG ZHAO* \\ Department of Respiratory Disease, The First Affiliated Hospital, Zhejiang University, \\ School of Medicine, Hangzhou 310003, Zhejiang, P.R. China \\ Received January 11, 2012; Accepted February 13, 2012
}

DOI: $10.3892 /$ or.2012.1741

\begin{abstract}
Epidermal growth factor receptor (EGFR) is one of the most promising targets for non-small cell lung cancer (NSCLC). Our study demonstrated the antitumor effects of icotinib hydrochloride, a highly selective epidermal growth factor receptor tyrosine kinase inhibitor (EGFR TKI), in two EGFR-mutated lung cancer cell lines compared to A549, a cell line without EGFR mutations. We incubated PC-9 and HCC827 human lung cancer cell lines both with (E746-A750) mutations with various concentrations of icotinib and gefitinib for $48 \mathrm{~h}$. Cell proliferation and migration were determined using a realtime cell invasion and migration assay and cytotoxicity assay. Apoptosis was assessed by measuring Annexin V staining using flow cytometry. The antitumor effects of icotinib compared to gefitinib were similar and were most effective in reducing the proliferation of EGFR-mutated cells compared to non-mutated controls. Our results suggest the possibility of icotinib as a new therapeutic agent of EGFR-mutated cancer cells, which has the potential to be used in the first-line treatment of EGFR-mutated NSCLC.
\end{abstract}

\section{Introduction}

Lung cancer is the second most common cancer and continues to be the leading cause of cancer-related deaths worldwide. More than $85 \%$ of lung cancer cases are categorized as non-small cell lung cancer (NSCLC) (1). Traditionally, lung cancer has been

Correspondence to: Dr Qiong Zhao, Present address: Department of Thoracic Oncology, The First Affiliated Hospital, Zhejiang University, School of Medicine, 79 Qingchun Road, Hangzhou 10003, Zhejiang, P.R. China

E-mail: yaoyinanwangyujia@163.com; doczq.2008@163.com

"Contributed equally

Key words: icotinib hydrochloride, epidermal growth factor receptor, exon 19 mutation, antitumor effect, non-small cell lung cancer, gefitinib treated with surgery, radiation and chemotherapy (2). The use of targeted therapies is increasing as the survival advantage for adjuvant chemotherapy is less than $5 \%$ with increased toxicity $(3,4)$. Although chemotherapy has been the standard of care for NSCLC patients, current clinical efforts are directed at targeted agents to improve outcome and reduce toxicity (5). The most common targeted agents that are being used in the treatment of NSLC include those that target key components in cancer cell signaling, such as the vascular endothelial growth factor receptor (VEGFR), platelet-derived growth factor receptor (PDGFR), insulin-like growth factor receptor (IGF-IR) and the epidermal growth factor receptor (EGFR) (5).

Epidermal growth factor stimulates the growth of epidermal and epithelial cells and in conjunction with its transmembrane receptor kinase is involved in cell proliferation, cell survival, adhesion, migration and cellular differentiation (6). The EGFR family consists of four transmembrane receptors including EGFR (HER1/erbB-1), HER2 (erbB-2/neu), HER3 (erbB-3) and HER4 (erbB-4) (6). Overexpression of EGFR and dysregulation of EGFR-mediated signaling pathways have been observed in tumors from more than $60 \%$ of the patients with metastatic NSCLC, contributing to tumorigenesis and leading to a poor prognosis (7).

Gefitinib (ZD1839, Iressa ${ }^{\circledR}$, AstraZeneca) is an EGFR tyrosine kinase inhibitor (TKI) approved by the Food and Drug Administration (FDA) in 2003 for treatment of non-small cell lung cancer (NSCLC). Clinical and biological analysis reveal a close correlation between somatic mutations of EGFR and EGFR-TKI's therapeutic efficacy $(8,9)$. In recent years, with the exception of gefitinib, many other EGFR-TKIs have been synthesized and evaluated for potential clinical activity (10-12). Recently, icontinib hydrochloride (BPI-2009H) has been used clinically in a phase I study to assess safety and efficacy in patients with advanced NSCLC and other solid tumors (13).

In this study, we evaluated the antitumor activity of a novel antitumor agent, icotinib hydrochloride \{4-[(3-ethynylphenyl) amino]-6,7-benzo-12-crown-4-quinazoline hydrochloride; BPI-2009H, Zhejiang Beta Pharma, Inc., Hangzhou, China\} an EGFR tyrosine kinase inhibitor in two different EGFRmutated human lung carcinoma cell lines as compared to a NSLC cell line without EGFR-mutations, and investigated the possible mechanism of its antitumor properties. 


\section{Materials and methods}

Cell culture and identification. The human cancer cell lines HCC827 (human lung adenocarcinoma with an acquired mutation in the EGFR tyrosine kinase domain (E746-A750 deletion) and A549 (human lung carcinoma, without mutations in E746-A750 were purchased from American Type Culture Collection (ATCC). The PC-9 (human lung adenocarcinoma with acquired mutation in E746-A750 was a gift from Professor Caichun Zhou (Shanghai Jiaotong University, Affiliated Chest Hospital). Cells were cultured in RPMI-1640 (PAA, Linz, Austria) medium or in DMEM (PAA) containing $10 \%$ fetal bovine serum (Hyclone, Logan, UT, USA) at $37^{\circ} \mathrm{C}$ in a $5 \% \mathrm{CO}_{2}, 95 \%$ air atmosphere. K-ras and EGFR mutations (exon 19, exon 21) in the extracted DNA of these three cell lines were examined using PCR-based direct sequencing assay (Takara Biotechnology Co., Ltd., Dalian, China).

Reagents and drug preparation. Icotinib hydrochloride (purity: 99\%, verified by high performance liquid chromatography) and gefitinib (purity: 99\%; J\&K-Chemical, Ltd., Beijing, China) were dissolved in dimethyl sulfoxide (SigmaAldrich, St. Louis, MO, USA) and diluted in saline solution to various final concentrations. 7-AAD and Annexin V-FITC were purchased from BD Biosciences (Franklin Lakes, NJ, USA).

Cell proliferation analysis by real-time cell electronic sensing. Briefly, $50 \mu \mathrm{l}$ of medium containing $10 \%$ FBS was added to 96-well plates to obtain background readings followed by the addition of $100 \mu \mathrm{l}$ of cell suspension containing an initial population of $5 \times 10^{4}$ PC-9, HCC 827 and A549 cells. The E-plates containing the cells were allowed to incubate at room temperature for $30 \mathrm{~min}$ before being placed on the device station in the incubator for continuous recording of impedance as reflected by cell index (CI). The CI value was automatically recorded once per $15 \mathrm{~min}$. As the cells grew on top of the microelectrodes in the micro wells, the CI increased. The cells were allowed to attach and spread typically for $24 \mathrm{~h}$ to reach a stable baseline before the addition of particle suspension. The cells were incubated for 20-22 $\mathrm{h}$ when CI reached a range of 1.0-1.2, indicating about $60 \%$ cell confluence, and the old culture medium was aspirated from the cells. Subsequently, $100 \mu \mathrm{l}$ of treatment medium containing DMSO or different concentrations of gefitinib $(20 \mathrm{nM}$ to $20 \mu \mathrm{M})$ or icotinib $(20 \mathrm{nM}$ to $20 \mu \mathrm{M})$ were added to each well. The sensor devices were mounted back to the device station in the incubator, and the CI in each well was automatically determined and recorded by a real-time cell electronic sensing (RT-CES ${ }^{\mathrm{TM}}$ ) system (ACEA Biosciences, San Diego, CA, USA) every $15 \mathrm{~min}$ for $72 \mathrm{~h}$. Calculation of the $\mathrm{IC}_{50}$ value was performed at the $72 \mathrm{~h}$ exposure period using the real-time cell analyzer (RTCA) software.

Cell migration assay by real-time cell invasion and migration. HCC827 migration was measured using a real-time cell invasion and migration (RT-CIM) assay system (ACEA Biosciences). Cells $\left(5 \times 10^{4} / \mathrm{ml}\right)$ were seeded in the upper chamber in basal medium containing $0.1 \%$ bovine serum albumin. The lower chamber contained various concentrations of gefitinib $(25,50$ or $100 \mathrm{nM})$ or icotinib $(25,50$ or $100 \mathrm{nM})$.
Cell migration was monitored every $15 \mathrm{~min}$ for a period of $24 \mathrm{~h}$.

Detection of cell apoptosis by flow cytometric analysis. Cells were incubated in 6-well plates and treated with icotinib or gefitinib at various concentrations for $48 \mathrm{~h}$ in a medium containing $5 \%$ fetal calf serum (FCS). Harvested cells were washed twice and resuspended at a concentration of $1 \times 10^{6}$ cells $/ \mathrm{ml}$ in binding buffer (pH 7.4, $10 \mathrm{mM}$ HEPES/NaOH, $140 \mathrm{mM} \mathrm{NaCl}, 2.5 \mathrm{mM}$ $\mathrm{CaCl}_{2}$ ). Next, cells were double-stained with Annexin V-FITC and 7-AAD for at $15 \mathrm{~min}$ at room temperature in the dark, and subsequently flow cytometry was performed with a 488-nm laser by fluorescence-activated cell sorting by using the FACSCalibur (BD Biosciences) within $1 \mathrm{~h}$. Cells stained only with Annexin V-FITC were considered to be viable apoptotic (VA) and cells stained with both 7-AAD and Annexin V-FITC were considered to be non-viable apoptotic (NVA).

Western blot analysis. After exposure to icotinib or gefitinib for $48 \mathrm{~h}$, PC-9 cells were lysed in $1 \mathrm{ml}$ of lysis buffer $(50 \mathrm{mM}$ Tris, pH 7.4, $150 \mathrm{mM} \mathrm{NaCl,1 \%}$ Triton X-100, 1\% sodium deoxycholate, $0.1 \%$ SDS, $2 \mathrm{mM}$ sodium pyrophosphate, $25 \mathrm{mM}$ $\beta$-glycerophosphate, $1 \mathrm{mM}$ EDTA, $1 \mathrm{mM} \mathrm{Na} \mathrm{VO}_{4}, 0.5 \mu \mathrm{g} / \mathrm{ml}$ leupeptin, $1 \mathrm{mM}$ PMSF). Subsequently, lysates were centrifuged at $16,000 \mathrm{rpm}$ for $5 \mathrm{~min}$ at $4^{\circ} \mathrm{C}$. Protein concentrations of the supernatants were determined by using BCA Protein Assay kit (23227, Thermo Scientific, Waltham, MA, USA). Samples containing $50 \mu \mathrm{g}$ of total protein were boiled and separated by SDS-PAGE (12\% SDS tricine gel), then transferred to polyvinylidene difluoride membranes. The membranes were blocked with $5 \%$ BSA and incubated overnight at $4^{\circ} \mathrm{C}$ with monoclonal anti-EGFR (15F8, CST-4405), anti-phospho-EGFR (Tyr1173, CST-4407), anti-MAPK (137FS, CST-4695), anti-phosphoMAPK (ERK1/2) (Thr202/Tyr 204, CST-4377), anti-Akt (CST-9272), anti-phospho-Akt (Ser473, CST-9272), anti- $\beta$-actin (13E5, CST-5057) (all of antibodies were purchased from Cell Signaling Technology, Danvers, MA, USA). Post-incubation with HRP-conjugated secondary Ab (1:3,000; Cell Signaling Technology) for $2 \mathrm{~h}$ at room temperature, membranes were washed extensively with $0.1 \%$ Tween-20 in TBS, and antigenic bands were visualized by ECL system (Thermo Scientific) according to the manufacturer's protocol.

Statistical analysis. The results are expressed as the mean value and standard error of the mean. Statistical significance was analyzed by one-way analysis of variance using SPSS17.0 (SPSS, Chicago, IL). $\mathrm{p}<0.05$ was considered statistically significant.

\section{Results}

Identification of EGFR mutations in genomic DNA from cell lines. EGFR mutations were present in PC-9 and HCC827 cell lines. Both cell lines harbored exon 19 deletions, the del E746-A750 (1) mutation for the PC-9 and the del E746-A750 (2) mutation for the HCC827 (Fig. 1). There were no exon 19 deletions in A549 cells. None of the cell lines had exon 21 L858R point mutation or codon 12 /codon 13 point mutation in the K-ras gene exon 1 according to PCR and direct sequencing. 


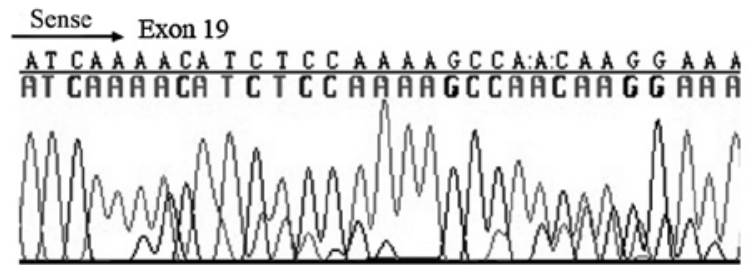

PC-9:Exon 19 del E746-A750(1) mutation

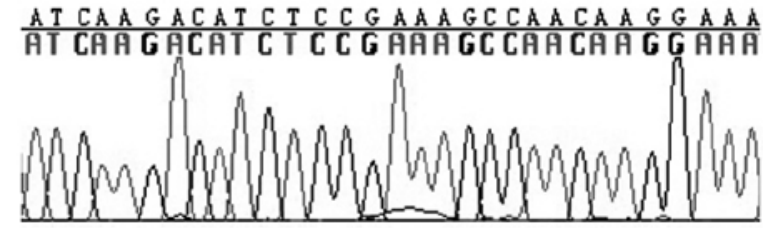

HCC827: Exon 19 del E746-A750(2) mutation

Figure 1. Identification of EGFR mutations in PC-9 and HCC827 cells. Exon 19 del mutations were detected in both cell lines.

Icotinib inhibits growth of EGFR-mutated non-small cell lung cancer cell lines. The effects of icotinib on the growth of EGFR-mutated NSCLC lines were determined using the RT-CES system assay. PC-9 cells, HCC827 cells and A549 cells were treated with increasing concentrations $(20 \mathrm{nM}$ to $20 \mu \mathrm{M}$ ) of icotinib for a duration of $72 \mathrm{~h}$ and compared to gefitinib (Fig. 2A). The cell index (CI) was used to represent cell status based on the measured electrical impedance (14). The calculation of frequency-dependent electrode impedance with or without cells present in the wells and the corresponding CI value has been previously described in detail (9). Icotinib achieved a $50 \%$ growth inhibition $\left(\mathrm{IC}_{50}\right)$ at concentrations of $<20 \mathrm{nmol} / 1$ in the PC-9 cell line and $<1.25 \mu \mathrm{mol} / 1$ in the HCC827 cell line, with almost the same cytotoxicity as gefitinib. However, in the A549 cell line, the $\mathrm{IC}_{50}$ was $8.8 \mu \mathrm{M}$ after treatment with icotinib and was $10.2 \mu \mathrm{M}$ after treatment with gefitinib.

Icotinib inhibits migration of EGFR-mutated non-small cell lung cancer cell lines. The effects of icotinib on growth of the HCC827 cell line were determined using the RT-CIS system assay (Fig. 2B). Compared to gefitinib, of which $100 \mathrm{nM}$ and $50 \mathrm{nM}$ could completely inhibit and $25 \mathrm{nM}$ could partially inhibit the migration of HCC827 cells, $100 \mathrm{nM}$ icotinib could obviously inhibit the migration, while $50 \mathrm{nM}$ had a slight inhibitory effect and $25 \mathrm{nM}$ had no effect.

Icotinib induces apoptosis in EGFR-mutated non-small cell lung cancer cell lines. To obtain a definitive quantification of the apoptosis effect, Annexin V-FITC and 7-AAD double staining methods were used to detect the percentage of apoptotic cells. Icotinib or gefitinib increased apoptosis of PC-9 and HCC827 cells in a concentration-dependent manner (Fig. 3A). The percentage of apoptotic PC-9 cells was elevated to $5.96 \pm 0.47,10.44 \pm 0.86$ and $14.70 \pm 0.24 \%$ after treatment with $0.1,1$ and $10 \mu \mathrm{M}$ icotinib, respectively, compared to $6.70 \pm 0.05,10.62 \pm 0.21$ and $16.71 \pm 1.37 \%$ after treatment with $0.1,1$ and $10 \mathrm{nM}$ gefitinib, respectively. In HCC827 cells, the percentages of apoptotic cells were elevated to $16.12 \pm 2.34$, $28.18 \pm 1.29$ and $43.70 \pm 1.49 \%$ after treatment with $0.1,1$ and $10 \mathrm{nM}$ icotinib, respectively, compared to $19.44 \pm 1.13$, $28.34 \pm 1.52$ and $49.29 \pm 2.13 \%$ after treatment with $0.1,1$ and $10 \mu \mathrm{M}$ gefitinib, respectively (Fig. 3B). The two drugs had almost the same capacity to induce EGFR-mutated NSCLC cell apoptosis.

Icotinib inhibits EGFR and MAPK, Akt phosphorylation in EGFR-mutated non-small cell lung cancer cell lines. To detect whether icotinib or gefitinib could inhibit phosphorylation of EGFR and EGFR-mediated downstream signaling, PC-9 cells were incubated with $0.1,1$ and $10 \mathrm{nM}$ icotinib or gefitinib for $48 \mathrm{~h}$ and subjected to western blot analysis. Our results indicate that both icotinib and gefitinib inhibited phosphorylation of EGFR, MAPK (ERK1/2) and Akt (Fig. 4).

\section{Discussion}

Epidermal growth factor receptor (EGFR)-mutant non-small cell lung cancer (NSCLC) was first defined in 2004 as a unique, clinically relevant molecular subset of lung cancer (15-17). This type of cancer is more sensitive to EGFR tyrosine kinase inhibitors (TKIs) and is associated with a better prognosis than EGFR wild-type NSCLC (17). EGFR is a 170-kDa glycoprotein, containing an extracellular ligand-binding domain, a transmembrane anchoring domain and an intracellular multifunctional tail that provides an ATP-binding site $(18,19)$. As a transmembrane tyrosine kinase, EGFR can trigger signal transduction pathways to regulate cell proliferation, migration and apoptosis, which are closely related to tumor progression $(20,21)$. Without doubt, EGFR is a promising target for antitumor treatment strategy. Chemotherapeutic agents that can potentially block EGFR-associated pathways will be much less toxic than traditional chemotherapy treatment regimens, as proven by using small molecular inhibitors that target EGFR tyrosine kinase (22). Up to now, many prospective clinical trials have focused mainly on gefitinib or erlotinib for patients with advanced NSCLC. Activating EGFR mutations have verified the benefit of EGFR TKIs in EGFR-mutant lung cancer $(23,24)$.

In 2009, the American Society of Clinical Oncology (ASCO) published a provisional clinical opinion that addressed the clinical utility of using EGFR mutation testing for patients with advanced NSCLC based on the results of five phase III randomized controlled trials (25). Although many EGFR mutations have been detected, the most common activated EGFR mutations are still exon 19 deletions that eliminate a leucine-arginine-glutamate-alanine motif in the tyrosine kinase domain of EGFR and exon 21 L858R (leucine substitution at amino acid 858) substitutions, together accounting for $85 \%$ of all EGFR mutations in NSCLC (26). Riely and coworkers revealed that EGFR mutations in exons 19 or 21 were correlated with clinical factors predictive of the response to EGFR TKIs (27), as patients with EGFR exon 19 deletions had significantly longer median progression-free survival (12 vs. 5 months) and median overall survival than patients with L858R (34 vs. 8 months) after treatment with erlotinib or 

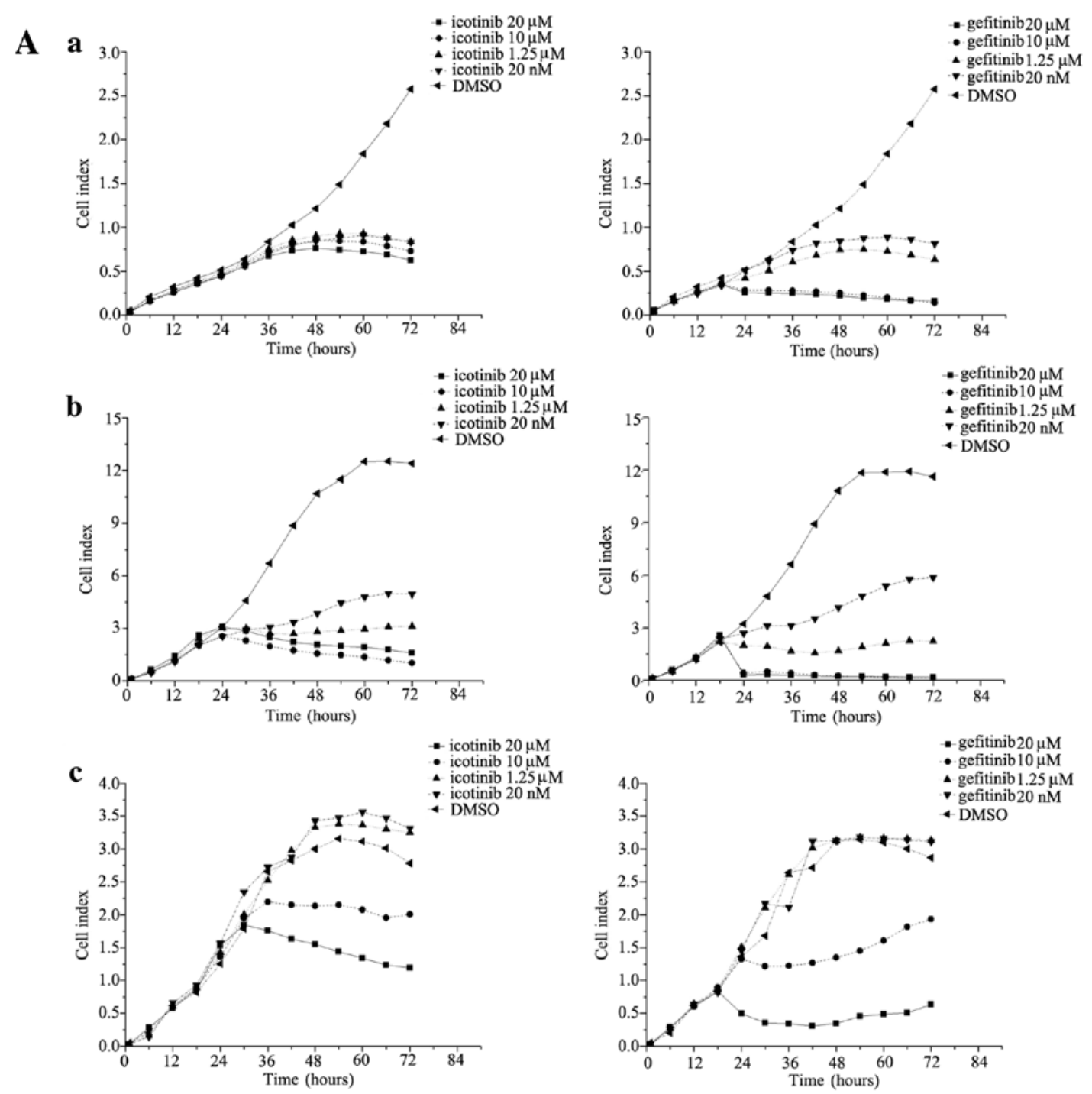

B $\mathbf{a}$

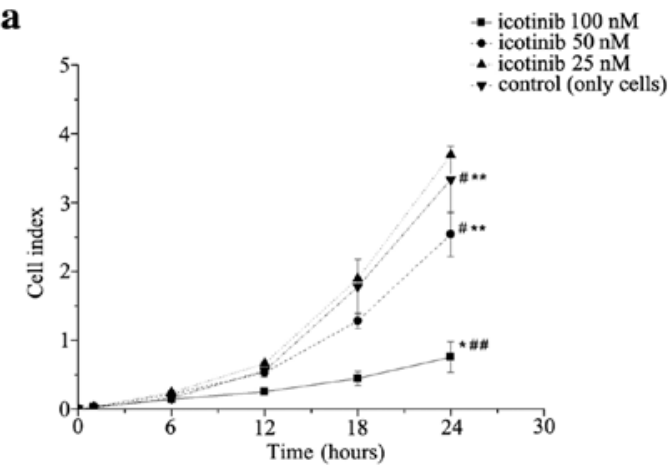

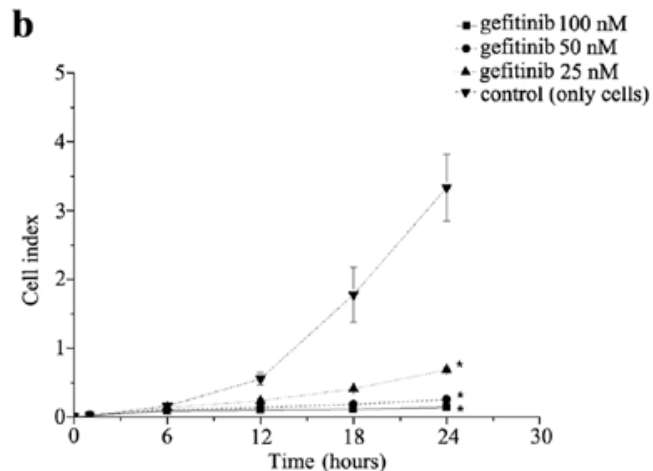

Figure 2. (A) Effect of icotinib and gefitinib on proliferation of (a) PC-9 cells, (b) HCC827 cells and (c) A549 cells as measured by RT-CEM. Different symbols represent different concentrations of drugs. Both icotinib and gefitinib exhibited a concentration-dependent anti-proliferative effect in PC-9 cells and in HCC827 cells, but did not have the same effect in A549 cells. (B) Effect of icotinib and gefitinib on the migration of HCC827 cells, as measured by RT-CIM. Different symbols represent differing concentrations of drugs. ${ }^{*} \mathrm{p}<0.05,{ }^{\#} \mathrm{p}>0.05$, compared to control (without any drugs); ${ }^{* *} \mathrm{p}<0.01,{ }^{\# \#} \mathrm{p}>0.05$ compared to cells treated with gefitinib $(n=3)$.

gefitinib. The possible mechanism accounting for the differing response between them might involve different mutations of EGFR, and their biological characteristics might regulate different responses to gefitinib, erlotinib and other EGFRTKIs with different structures.
Unfortunately, typical remissions in NSCLC treatment using EGFR-TKIs only last for 4-6 months (28), accompanied with acquired drug resistance that limits the prolonged efficacy of currently available TKIs. The T790M mutation in EGFR is found in 50\% of clinically EGFR-mutated 
A

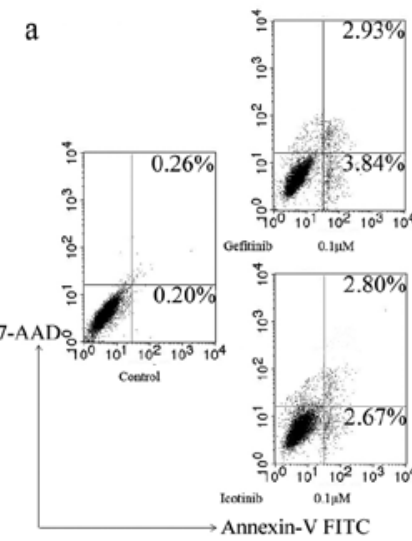

b

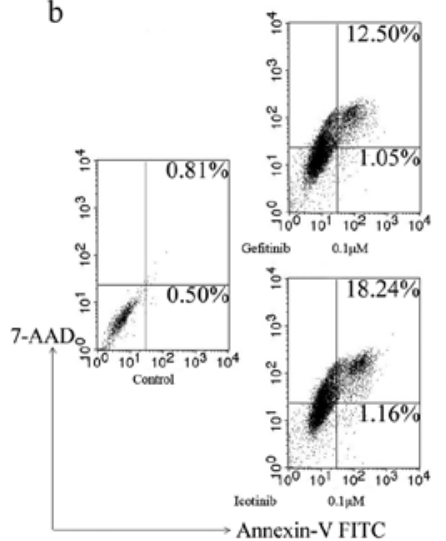

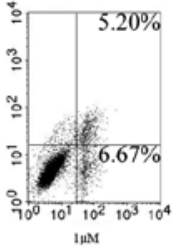
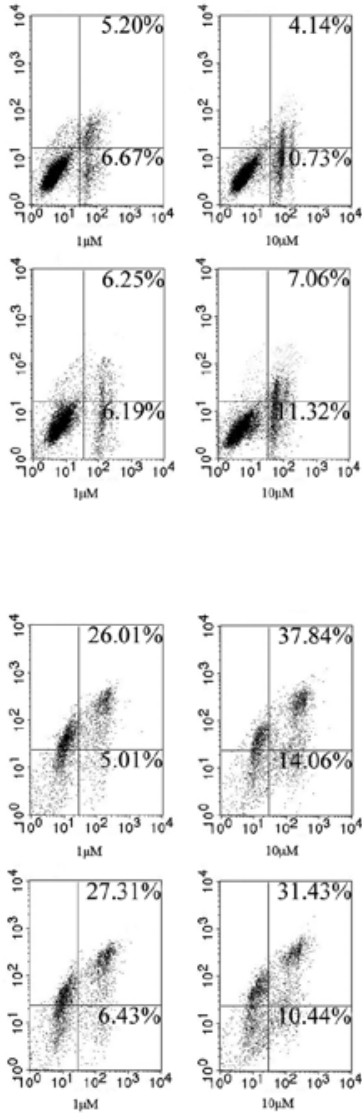

B

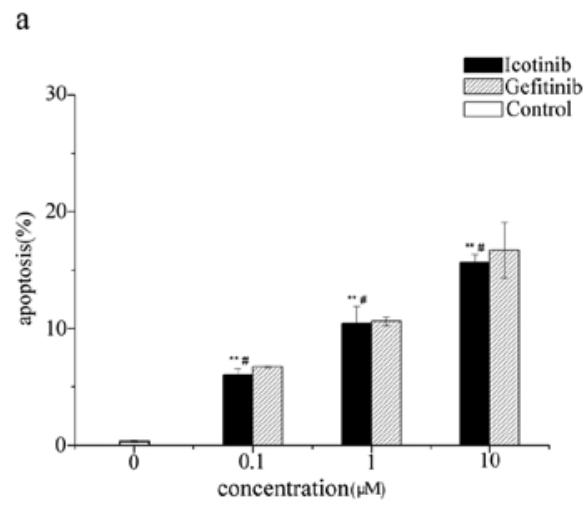

b

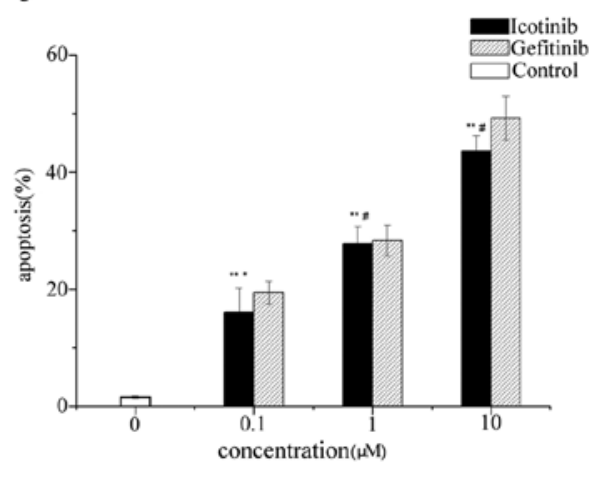

Figure 3. (A) The effect of icotinib and gefitinib on inducing apoptosis of (a) PC-9 cells and (b) HCC827 in vitro. Apoptotic cells were detected by Annexin V-FITC and 7-AAD double staining methods after treatment for $48 \mathrm{~h}$. Both drugs induced apoptosis of EGFR-mutated NSCLC cells in a dose-dependent manner. (B) The percentage of apoptotic cells (a, PC-9; b, HCC827), ${ }^{* *} \mathrm{p}<0.01$, compared to control (without any drugs); ${ }^{*} \mathrm{p}>0.05$, ${ }^{*} \mathrm{p}<0.05$, compared to gefitinib ( $\mathrm{n}=3$ ).

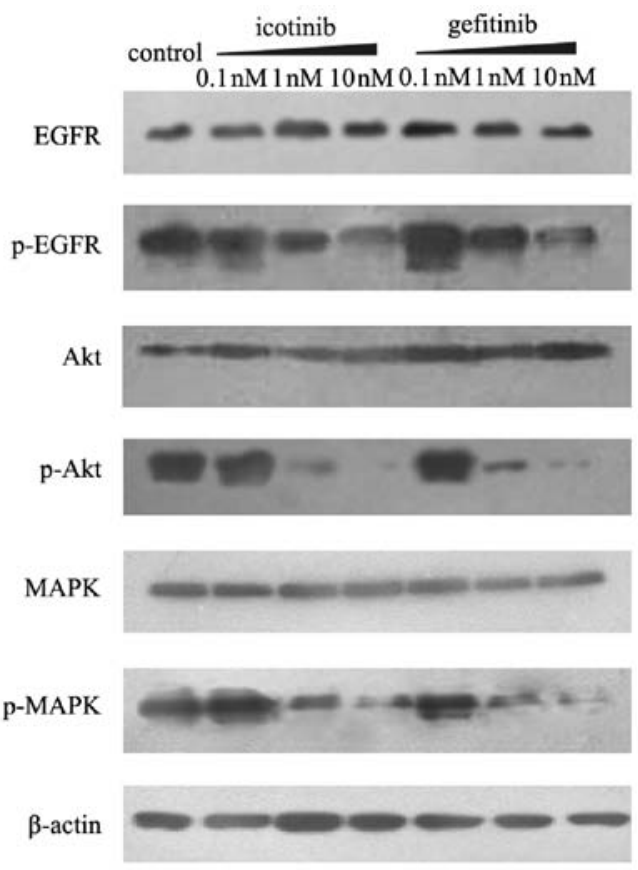

Figure 4. Effect of icotinib and gefitinib on EGFR phosphorylation, and MAPK, Akt activation in EGFR-mutated NSCLC cell lines. PC-9 cells were treated for $48 \mathrm{~h}$ with icotinib or gefitinib. Total EGFR and phospho-EGFR, total Akt and phospho-Akt, total p42/44 MAPK and phospho-p42/44 MAPK levels were analyzed by western blotting. Both icotinib and gefitinib inhibited EGFR, Akt and MAPK phosphorylation. patients with acquired resistance to erlotinib or gefitinib $(29,30)$. L858R mutations are likely to be concomitant with T790M and confer gefitinib resistance in NSCLC patients (31), as T790M mutation increases the ATP affinity of the EGFR-L858R mutant $(32,33)$. It has been suggested that the suppression of STAT3 may potentiate the antitumor effects of EGFR TK inhibitors (34). Additionally, the use of histone deacetylase inhibitors may be an effective treatment option to potentiate the effects of EGFR TKIs in NSCLC with activating K-ras mutations (35). Consequently, further progress is anticipated from the development of other novel TKIs with an emphasis on approaches to overcome drug resistance.

Here, we investigated the effect of a novel tyrosine kinase inhibitor, icotinib hydrochloride, on EGFR-mutated non-small cell lung cancer cells and its associated mechanisms. As exon 19 deletions occur more commonly than L858R mutations in Asia (22), we therefore selected PC-9 and HCC827 cells, both with exon 19 deletions (Fig. 1).

Our study has demonstrated that icotinib selectively inhibited EGFR, as evidenced by its inhibition of EGFR activity and the lack of inhibition of the Abl-related gene (Arg) tyrosine kinase (data not shown). Furthermore, we examined the specificity of icotinib against 88 other kinases using the selective-inhibition assay. Icotinib selectively inhibited the EGFR members including some mutated forms with different inhibition efficacies. Among them, we found that icotinib 
obviously inhibited EGFR (L858R), with $1 \%$ kinase activity level after treatment with icotinib.

Moreover, we showed that icotinib inhibited cell proliferation in EGFR-mutated non-small cell lung cancer cell lines (PC-9 and HCC827 cells) in a dose-dependent manner, similarly to gefitinib. Both icotinib and gefitinib induced apoptosis in PC-9 and HCC827 cells and there was no statistically significant difference between them $(p>0.05)$. This is of clinical importance as gefitinib is considered the standard first-line therapy for NSCLC patients with EGFR mutations $(36,37)$ which warrants the clinical evaluation of icotinib (13). The results are timely as icotininb was recently evaluated in 36 NSCLC patients that failed prior platinum-based chemotherapy in a phase I clinical trial (13). The results demonstrated that oral icotinib was well tolerated with minimal toxicity and showed positive clinical antitumor responses (13).

We also investigated the effect of icotinib on the EGFR signaling pathways. In our study, treated with icotinib or gefitinib could obviously inhibit EGFR, MAPK (ERK1/2) and Akt phosphorylation in PC-9 cells as seen by western blot analysis. The MAPK/ERK pathway is a chain of proteins in the cell that communicates a signal from a receptor on the surface of the cell to genes in the nucleus of the cell that are involved in cell growth, proliferation, differentiation, migration and apoptosis. The constitutive activation of MAPK/ERK signalling is of particular relevance to cancer (38). Akt is a serine/threonine protein kinase that plays a key role in multiple cellular processes, including cellular survival pathways, by inhibiting apoptotic processes, which is implicated as a major factor in many types of cancer (39). Thus our findings suggest that icotinib may exert its antitumor activity through abolishment of constitutive MAPK and Akt phosphorylation.

In conclusion, icotinib hydrochloride shows promising antitumor activity as a specific EGFR inhibitor in EGFRmutated NSCLC cell lines compared with gefitinib, the current standard of care, and gives a new choice of EGFR-TKIs for patients. Moving forward, a phase II clinical trial will need to be conducted to support personalized targeted therapies depending on the specific EGFR-TKIs directed to specific EGFR mutations.

\section{References}

1. Jemal A, Siegel R, Ward E, Hao Y, Xu J and Thun MJ: Cancer statistics, 2009. CA Cancer J Clin 59: 225-249, 2009.

2. Moran C: Importance of molecular features of non-small cell lung cancer for choice of treatment. Am J Pathol 178: 1940-1948, 2011.

3. Carbone DP and Felip E: Adjuvant therapy in non-small cell lung cancer: future treatment prospects and paradigms. Clin Lung Cancer 12: 261-271, 2011.

4. Wong HL and de Boer RH: Vandetanib for the treatment of non-small cell lung cancer. Exp Opin Pharmacother 12: 2271-2278, 2011.

5. Belani CP, Goss G and Blumenschein G Jr: Recent clinical developments and rationale for combining targeted agents in non-small cell lung cancer (NSCLC). Cancer Treat Rev 37: 173-184, 2012.

6. Leung K: ${ }^{124}$ I-Labeled anti-HER2-specific C6.5 diabody. In: Molecular Imaging and Contrast Agent Database (MICAD) (Internet). National Center for Biotechnology Information (US), Bethesda, MD; 2004-2011, 2011.

7. Gazdar AF: Activating and resistance mutations of EGFR in non-small cell lung cancer: role in clinical response to EGFR tyrosine kinase inhibitors. Oncogene 28: S24-S31, 2009.
8. Riely GJ, Politi KA, Miller VA and Pao W: Update on epidermal growth factor receptor mutations in non-small cell lung cancer. Clin Cancer Res 12: 7232-7241, 2006.

9. Fukuoka M, Wu Y, Thongprasert S, et al: Biomarker analyses from a phase III, randomized, open-label, first-line study of gefitinib (G) versus carboplatin/paclitaxel $(\mathrm{C} / \mathrm{P})$ in clinically selected patients (pts) with advanced non-small cell lung cancer (NSCLC) in Asia (IPASS). J Clin Oncol 29: 2866-2874, 2011.

10. Eskens FA, Mom CH, Planting AS, et al: A phase I dose escalation study of BIBW 2992, an irreversible dual inhibitor of epidermal growth factor receptor 1 (EGFR) and 2 (HER2) tyrosine kinase in a 2-week on, 2-week off schedule in patients with advanced solid tumours. Br J Cancer 98: 80-85, 2008.

11. Erlichman C, Hidalgo M, Boni JP, et al: Phase I study of EKB-569, an irreversible inhibitor of the epidermal growth factor receptor, in patients with advanced solid tumors. J Clin Oncol 24: 2252-2260, 2006.

12. Mendelsohn J and Baselga J: Epidermal growth factor receptor targeting in cancer. Semin Oncol 33: 369-385, 2006.

13. Zhao Q, Shentu J, Xu N, et al: Phase I study of icotinib hydrochloride (BPI-2009H), an oral EGFR tyrosine kinase inhibitor, in patients with advanced NSCLC and other solid tumors. Lung Cancer 73: 195-202, 2011.

14. Xing JZ, Zhu L, Jackson JA, et al: Dynamic monitoring of cytotoxicity on microelectronic sensors. Chem Res Toxicol 18: 154-161, 2005.

15. Lynch TJ, Bell DW, Sordella R, et al: Activating mutations in the epidermal growth factor receptor underlying responsiveness of non-small cell lung cancer to gefitinib. N Engl J Med 350: 2129-2139, 2004.

16. Paez JG, Jänne PA, Lee JC, et al: EGFR mutations in lung cancer: correlation with clinical response to gefitinib therapy. Science 304: 1497-1500, 2004

17. Pao W, Miller V, Zakowski M, et al: EGF receptor gene mutations are common in lung cancers from 'never smokers' and are associated with sensitivity of tumors to gefitinib and erlotinib. Proc Natl Acad Sci USA 101: 13306-13311, 2004.

18. Yarden Y: The EGFR family and its ligands in human cancer signaling mechanisms and therapeutic opportunities. Eur J Cancer 37: S3-S8, 2001.

19. Janmaat ML and Giaccone G: The epidermal growth factor receptor pathway and its inhibition as anticancer therapy. Drugs Today 39: 61-80, 2003.

20. Jorissen RN, Walker F, Pouliot N, Garrett TP, Ward CW and Burgess AW: Epidermal growth factor receptor: mechanisms of activation and signaling. Exp Cell Res 284: 31-53, 2003.

21. Kari C, Chan TO, Rocha de Quadros M and Rodeck U: Targeting the epidermal growth factor receptor in cancer: apoptosis takes center stage. Cancer Res 63: 1-5, 2003.

22. Mok TS, Wu YL, Thongprasert S, et al: Gefitinib or carboplatinpaclitaxel in pulmonary adenocarcinoma. N Engl J Med 361: 947-957, 2009.

23. Shepherd FA, Rodrigues Pereira J, Ciuleanu T, et al: Erlotinib in previously treated non-small cell lung cancer. N Engl J Med 353: 123-132, 2005.

24. Thatcher N, Chang A, Parikh P, et al: Gefitinib plus best supportive care in previously treated patients with refractory advanced non-small cell lung cancer: results from a randomised, placebo-controlled, multicentre study (Iressa Survival Evaluation in Lung Cancer). Lancet 366: 1527-1537, 2005.

25. Keedy VL, Temin S, Somerfield MR, et al: American Society of clinical oncology provisional clinical opinion: epidermal growth factor receptor (EGFR) mutation testing for patients with advanced non-small cell lung cancer considering first-line EGFR tyrosine kinase inhibitor therapy. J Clin Oncol 29: 2121-2127, 2011.

26. Pan Q, Pao W and Ladanyi M: Rapid polymerase chain reactionbased detection of epidermal growth factor receptor gene mutations in lung adenocarcinomas. J Mol Diagn 7: 396-403, 2005.

27. Riely GJ, Pao W, Pham D, et al: Clinical course of patients with non-small cell lung cancer and epidermal growth factor receptor exon 19 and exon 21 mutations treated with gefitinib or erlotinib. Clin Cancer Res 12: 839-844, 2006.

28. Felip E and Rosell R: Clinical experience with erlotinib in non-small cell lung cancer. Drugs Today (Barc) 42: 147-156, 2006.

29. Nguyen KS, Kobayashi S and Costa DB: Acquired resistance to epidermal growth factor receptor tyrosine kinase inhibitors in non-small cell lung cancers dependent on the epidermal growth factor receptor pathway. Clin Lung Cancer 10: 281-289, 2009. 
30. Zhou W, Ercan D, Chen L, et al: Novel mutant-selective EGFR kinase inhibitors against EGFR T790M. Nature 462: 1070-1074, 2009.

31. Yokoyama T, Kondo M, Goto Y, et al: EGFR point mutation in non-small cell lung cancer is occasionally accompanied by a second mutation or amplification. Cancer Sci 97: 753-759, 2006.

32. Yun CH, Mengwasser KE, Toms AV, et al: The T790M mutation in EGFR kinase causes drug resistance by increasing the affinity for ATP. Proc Natl Acad Sci USA 105: 2070-2075, 2008.

33. Sos ML, Rode HB, Heynck S, et al: Chemogenomic profiling provides insights into the limited activity of irreversible EGFR inhibitors in tumor cells expressing the T790M EGFR resistance mutation. Cancer Res 70: 868-874, 2010.

34. Chiu HC, Chou DL, Huang CT, et al: Suppression of Stat3 activity sensitizes gefitinib-resistant non-small cell lung cancer cells. Biochem Pharmacol 81: 1263-1270, 2011.

35. Kurtze I, Sonnemann J and Beck JF: KRAS-mutated non-small cell lung cancer cells are responsive to either co-treatment with erlotinib or gefitinib and histone deacetylase inhibitors or single treatment with lapatinib. Oncol Rep 25: 1021-1029, 2011.
36. de Lima Lopes G Jr, Segel JE, Tan DS, Do YK, Mok T and Finkelstein EA: Cost-effect- tiveness of epidermal growth factor receptor mutation testing and first-line treatment with gefitinib for patients with advanced adenocarcinoma of the lung. Cancer 118: 1032-1039, 2012.

37. Costanzo R, Piccirillo MC, Sandomenico C, et al: Gefitinib in non-small cell lung cancer. J Biomed Biotechnol 2011: 815269, 2011.

38. Orton RJ, Sturm OE, Vyshemirsky V, Calder M, Gilbert DR and Kolch W: Computational modelling of the receptor-tyrosinekinase-activated MAPK pathway. Biochem J 392: 249-261, 2005.

39. Freeman-Cook KD, Autry C, Borzillo G, et al: Design of selective, ATP-competitive inhibitors of Akt. J Med Chem 53: 4615-4622, 2010 